\title{
WHEN THE PERFORMANCE COMES INTO PLAY: THE INFLUENCE OF POSITIVE ONLINE CONSUMER REVIEWS ON INDIVIDUALS' POST- CONSUMPTION RESPONSES
}

\begin{abstract}
Although the research on online consumer reviews (OCRs) is broad, several important gaps still exist. This paper aims to bridge some of these gaps by studying the influence of positive OCRs (pOCRs) on post-consumption responses, namely attitude toward the firm and repurchase intentions. It differentiates between whether the performance level during consumption was high or low, that is, whether the product met the objectives set by the consumers. To this end, the paper addresses pOCRs in a twofold approach. First, it analyzes the effect of positive valence intensity, considering neutral-indifferent, moderately positive, and extremely positive OCRs. Second, it tests the influence of individuals' perceived positivity of OCRs. The results show that the same pOCRs may have a positive or a negative influence on individuals' post-consumption responses depending on the performance. Accordingly, the relationship between perceived positivity and post-consumption responses follows U-shaped functional forms.
\end{abstract}

\section{Keywords}

Online consumer review; performance level; positive valence intensity; perceived positivity; post-consumption responses; U-shaped functional form. 
WHEN THE PERFORMANCE COMES INTO PLAY: THE INFLUENCE OF POSITIVE ONLINE CONSUMER REVIEWS ON INDIVIDUALS' POST-

\section{CONSUMPTION RESPONSES}

\section{Introduction}

You are going to attend a Bruno Mars concert with a good friend. You are both fans of this artist, so, although there are other events that you would like to see, you have chosen this one. When the concert ends and you leave the stadium, you start talking about it. (S)he does not understand why the artist did not sing some of his greatest hits, considers that the performance was unspectacular, and thinks that the concert was short. In contrast, you are delighted with the concert. You think that the songs that he played were amazing, the performance was fantastic, and that the concert was of an acceptable length. Why are your opinions of the same concert so different? Why does your friend regret his/her decision while you are willing to repeat it? When you talk a little more, your friend explains that (s)he had proposed that you both attended this concert because (s)he had read very positive reviews about it on the Internet. On the contrary, although you had also read the online opinions of other fans, they were not very positive and did not exceed an average score of 3 out of 5 . From this situation, the following question arises: Are online consumer reviews important after the purchase?

Online consumer reviews (OCRs) are a specific form of electronic word of mouth (eWOM) that typically contain advice, opinions, and comments from other consumers; they are also normally perceived as unbiased and trustworthy. In recent years they have become a major source of information that allow consumers to search for and find products that match their preferences and to make better purchase decisions (Chen \& Xie, 2008; Ye et al., 2011). Research has shown that, when making purchase decisions, $85 \%$ of consumers trust online reviews as much as personal recommendations (BrightLocal, 2017). Thus, many firms host 
OCRs on their websites to motivate consumers to actively collaborate with them and to promote different kinds of interactions (Shi \& Liao, 2017).

Marketing practitioners and researchers have explored the aspects of OCRs that are important for increasing their effectiveness, the valence of the message being one of the most frequently studied. It would be logical to think that OCRs with positive valence will have positive influence on aspects such as perceived usefulness, satisfaction, and purchase intentions. In fact, most empirical research has found positive linear relationships between OCR valence and these variables (e.g., Moe \& Trusov, 2011; Pan \& Chiou, 2011; Tsao et al., 2015).

Despite the large number of studies into OCR valence, two important gaps in the research can be identified. First, previous studies have focused on the importance of OCRs when consumers make their choice, applying a transactional perspective that addresses the finalization of the purchase after reading the reviews (e.g., Sparks \& Browning, 2011). Nevertheless, how these OCRs condition the later relationship between the firm and customers remains largely unexplored. Second, previous studies have not considered that the performance level may modify the influence exerted by OCRs during the purchase, leading to relationships that are different from the linear and positive functional forms traditionally proposed in the literature. In fact, to our knowledge, very few papers have tested negative effects and/or non-linear functional forms to more accurately assess the influence of OCRs (Duverger, 2013; Park \& Nicolau, 2015).

The present paper aims to fill these gaps by studying the influence of positive OCRs (pOCRs) on individuals' responses after consumption, namely their attitude toward the firm and repurchase intentions. With this aim, it differentiates between whether the performance level during consumption was high or low, that is, whether the product met the objectives set by the consumers (Zeelenberg et al., 2000). Thus, the different responses that individuals 
have toward a performance are analyzed to assess the effect of the OCRs that they had read before making their decisions. The paper deals with the influence of pOCRs by applying a twofold approach. First, it focuses on positive valence intensity, comparing the influence of neutral-indifferent, moderately positive, and extremely positive OCRs. Second, it examines individuals' perception of the positivity of OCRs and proposes testing U-shaped functional forms. Two theoretical approaches are combined: expectation confirmation theory (ECT) (Oliver, 1977) and social judgment theory (SJT) (Sherif \& Hovland, 1961).

The methodology applied is based on an experimental study, in which positive valence intensity and performance level are manipulated, and individuals' perceptions about OCRs and post-consumption responses are measured. The paper focuses on experience services, because post-consumption responses are especially important in situations where individuals cannot discern and evaluate product attributes before consumption (Chua et al., 2017; Lee \& Youn, 2009; Park \& Nicolau, 2015). Individuals require more external information to reduce uncertainty and perceived risks, so they usually rely on word of mouth (WOM) and electronic WOM (eWOM) to make inferences about quality and even to interpret the outcomes obtained from consumption (Wirtz \& Chew, 2002). In this way, OCRs, which typically contain advice and comments from experienced consumers, are perceived as being more credible than other information sources, enhance purchasing decisions, and condition perceptions about outcomes (Park \& Lee, 2009; Yoo \& Gretzel, 2008).

This paper makes two main academic contributions. First, it explores the highly important but understudied influence of pOCRs on individuals' post-consumption responses. It extends beyond the immediate influence of pOCRs on purchase decision-making and overcomes the problems of the transactional perspective that the previous literature has applied. Thus, the present paper sheds light on the importance of pOCRs on the relationship that the customer establishes with the firm after consumption. Second, it provides theoretical 
development and empirical support to explain different effects and functional forms associated with pOCRs. In contrast to previous research, which considered only linear and positive effects, this paper demonstrates that the same pOCR can exert negative or positive effects depending on whether performance level during consumption was high or low. Moreover, it shows that the relationships between individuals' perceived positivity of OCRs and their post-consumption responses follow U-shaped functional forms, introducing a new research perspective of customer interactions through social media.

\section{OCR valence: research gaps and questions}

OCR valence is defined as the evaluative direction of recommendations, positive or negative (Koo, 2015). Positive OCRs highlight the strengths of a product, encourage readers to purchase it, and lead to positive attitudes (Dellarocas et al., 2007; Duan et al., 2008; Pan \& Chiou, 2011). On the contrary, negative OCRs describe the problems related to a product, discourage readers from purchasing it, and strengthen negative attitudes. In this way, positive (negative) OCRs are assumed to increase (decrease) the probability of customers choosing a product, obtaining better (worse) company sales and profits (Dellarocas et al., 2007; Wang et al., 2015). Although the research on OCR valence is broad (see, for example, Floyd et al., 2014 for a meta-analysis), important gaps still exist. This paper focuses its attention on two main issues and proposes relevant research questions.

First, it should be borne in mind that the influence of OCR valence has consistently been studied during the same stages of the decision-making process, namely those related to the consumers' purchase decisions (Gilly et al., 1998; Liu, 2006). In these stages consumers employ OCRs to collect information about different products, to form their expectations about consumption, to enhance their evaluation of alternatives, and to optimize their choice (e.g., Casalo et al., 2015; Hu \& Li, 2011; Kostyra et al., 2016). Thereby, previous research 
has demonstrated the influence of valence on the variables related to individuals' perceptions about OCRs and purchase behavior, applying a transactional perspective. Nevertheless, it has not dealt with the role of OCRs after the consumption experience, when individuals can determine the adequacy of the performance obtained.

Second, prior research has assumed that the influence of pOCRs is always linear and monotonic, which means that it remains constant both in direction and in intensity. In other words, the more (less) positive that OCRs are, the better (worse) will be the perceptions that individuals will have about the product, and the more (less) positive will be their attitudes toward the firm, and the higher (lower) will be their satisfaction. Contrary to this traditional focus, some studies have benefitted from testing curvilinear functional forms. For example, Heimbach and Hinz (2016) revealed that the relationship between positive online contents and virality follows an inverted U-shaped pattern. Similarly, Park and Nicolau (2015) demonstrated that OCRs with extreme ratings (positive or negative) are more useful and enjoyable than OCRs with moderate ratings, proposing asymmetric U-shaped lines. Finally, Duverger (2013) showed that user-generated content has curvilinear effects on market share. Overall, it is notable that these studies have all compared extremely positive and extremely negative contents that individuals read before the purchase and analyzed their effects on individuals' immediate reactions to the information. Nevertheless, they have not addressed the suitability of testing U-shaped functional forms to study the influence of different levels of positivity on the individual-firm relationship after consumption (e.g., attitude toward the firm and repurchase intentions).

If performance comes into play and non-linear functional forms are taken into account, two fundamental research questions emerge: How do positive OCRs influence individuals' post-consumption responses? What is the real and complex nature of the relationship between individuals' perceived positivity and their post-consumption responses? 
The present paper addresses these questions to understand the influence of pOCRs on individuals' responses after the purchase. It does not take for granted that linear models are the most appropriate analytical instruments and, in accordance with the papers already cited, proposes testing U-shaped functional forms after consumption. Similarly, it justifies apparently contradictory effects to those initially detected during the purchase.

\section{The decision-making process and OCRs: the importance of individuals' post- consumption responses}

The decision-making process covers the customer's journey before, during, and after purchasing a product (Nicosia, 1966). It was initially proposed by Engel et al. (1968), who suggested a five-stage model to study consumer behavior: the need for recognition, search for information, evaluation, purchase decision, and post-purchase behavior. Subsequently, postpurchase behavior was divided into two more specific stages: consumption (i.e., product usage) and post-consumption responses (Blackwell et al., 2005). This paper emphasizes the importance of studying the role of OCRs during the post-consumption stage (Schindler \& Bickart, 2005), for which it is also necessary to understand their influence during the purchase.

Individuals read OCRs as part of their decision-making processes, to acquire information, to reduce uncertainty, and to analyze the different alternatives (Bronner \& de Hoog, 2011). At this stage, the valence intensity of OCRs is a fundamental variable, because it reflects the strength of the author's recommendation (Lee \& Pee, 2013; Mudambi \& Schuff, 2010). Extremely positive OCRs clearly point out the benefits of choosing a product, so they make the reader aware of the benefits of making the purchase, generating product sales (Moe \& Trusov, 2011; Park \& Lee, 2009; Yoo \& Gretzel, 2008). On the contrary, neutral-indifferent OCRs do not contain either positive or negative claims, and they usually 
seem to be insufficiently interesting, novel, or controversial to motivate customers (Liu, 2006; Tang et al., 2014). Thus, these OCRs are not considered to be influential, and lead individuals to manifest low purchase intentions (Forman et al., 2008; Pavlou \& Dimoka, 2006).

During consumption, individuals directly interact with the product, and thus can evaluate its adequacy in meeting the objectives that motivated its purchase. Next, they define their post-consumption responses, replacing previous evaluations, based on their experience throughout the whole decision-making process. Post-consumption responses most accurately reflect the reality of consumers' attitudes and behavior, and are characterized by their durability, stability and realism (Bhattacherjee, 2001). They explain why a customer remains loyal to a firm to its financial benefit and enable the prediction of his/her future behavior (Pansari \& Kumar, 2017). Hence, post-consumption responses should be considered key variables to design strategies that aim to manage the whole customer decision-making process, personalizing individual-firm relationships and generating engagement beyond mere transactions.

Post-consumption responses are especially important in situations where individuals cannot assess product quality before consumption, as happens with experience services (Beerli-Palacio \& Martin-Santana, 2017; Grace \& O’Cass, 2001). In these situations, purchase decisions are supported by assumptions and intuitions that individuals relativize after using the service. For example, tourists often purchase their travel packages several months before taking their holidays, with no specific knowledge of the intended destination. After holidays, tourists define their responses considering not only the information that prompted their initial choice but also their direct experience at the destination.

Although post-consumption responses are essential variables in marketing, very few works have studied them, and even less have addressed the role of OCRs. We can identify 
two research lines based on the post-consumption responses analyzed: (1) emotions and (2) satisfaction-behavioral intentions.

The first line examines the relationship between emotions that individuals experience after consuming a product and future behavior (Chang et al., 2014; Hosany \& Prayag, 2013). Individuals' post-consumption emotions influence their repurchase intentions and WOM transmission (Jang \& Namkung, 2009; Walsh et al., 2011). Some works have distinguished between immediate post-consumption emotions, which accurately reflect the original experience, and delayed emotions, which depend on memory and include distortions (Aaker et al., 2008; Chang et al., 2014; Xu \& Schwartz, 2009). These distortions may be caused by other customers' opinions, such as OCRs, and can evoke new and different emotions based on the same experience (Loftus, 1975, 1979). In this line, Cowley (2014) stated that remembering and explaining the consumption experience to others makes individuals relive and amplify their post-consumption emotions, feeling more pleasure if the experience was positive and more pain if the experience was negative.

The second line analyzes individuals' satisfaction and the behavioral intentions that they display after consumption (Kim et al., 2016; Triantafillidou \& Siomkos, 2014). These responses are developed from the comparison between individuals' perceptions about outcomes (formed during consumption) and initial expectations (defined before consumption) (Xu, 2019). According to expectation confirmation theory (ECT) (Oliver, 1977, 1980), this comparison determines confirmation, positive disconfirmation, or negative disconfirmation, depending on the agreement between the two aspects (Oliver, 1980; Tse \& Wilton, 1988). Confirmation occurs when outcomes match consumers' expectations and encourages them to feel balanced and neutral, while disconfirmation arises from discrepancies between outcomes and expectations. If the outcomes are significantly better than expected, positive disconfirmation occurs, so consumers experience satisfaction and show repurchase intentions. 
However, if outcomes are significantly worse than expected, consumers suffer negative disconfirmation and negative behavioral responses emerge (Cadotte et al., 1987; Kim et al., 2016). This research line has been adapted to study satisfaction and continuance intention to use information technologies (Bhattacherjee, 2001; Oghuma et al., 2016).

Based on this popular view of (dis)satisfaction formation, it is worth highlighting Chan and Cui (2011)'s article that demonstrated two potential contrasting effects of negative WOM on consumer dissatisfaction: aggravating effect, based on attitude polarization, and alleviating effect, based on downward comparison. On the one hand, aggravating effect posits that individuals' attitudes become more extreme after exposure to and/or communication about attitude-congruent information (Abelson, 1995; Chan \& Cui, 2011; Eagly \& Chaiken, 1993). Thus, individuals' opinions are polarized by the points of view expressed by others in OCRs, in terms of evaluation of arguments, beliefs and opinions about their own consumption (Abelson, 1995; Eagly \& Chaiken, 1993). On the other hand, alleviating effect demonstrates that others' experiences may influence the standard against which the individual's consumption experience is compared. This effect is based on downward comparisons and establishes that individuals feel more comfortable about an unpleasant situation when they perceive that their own situation is better than those of others (e.g., Dias \& Lobel, 1997; Helgeson \& Taylor, 1993). Thus, negative reviews make individuals aware of negative experiences shared by less fortunate consumers, which reduces stress, improves mood, and generates satisfaction (Buunk \& Gibbons, 2007).

The present paper is framed within the second research line and studies postconsumption responses by focusing on individuals' attitude toward the firm and repurchase intentions. It proposes that OCRs read by individuals before the purchase play a fundamental role in the definition of post-consumption responses, because they act as a baseline level that sets prior expectations and later consumption perceptions (Kim et al., 2016; Yim et al., 2007). 
Overall, understanding how consumers use pOCRs to develop their post-consumption responses is a fundamental issue for any firm that aims to enhance its long-term relationships with customers.

\section{The influence of positive OCRs after consumption}

\subsection{How does the positive valence intensity of OCRs influence individuals' post-consumption} responses?

Examining the role of the positive valence intensity of OCRs on the formation of individuals' post-consumption responses must take into account that different influences may exist depending on whether the performance level was high or low.

When performance is high, the benefits of the product are high and individuals achieve their objectives (Olshavsky \& Miller, 1972; Zeelenberg et al., 2000). In these circumstances, if individuals have read extremely positive OCRs before the purchase, they hold very high expectations that are in consonance with the performance. This consonance makes individuals endorse the information provided by the pOCRs and adapt their own outcome perceptions to them (Bone, 1995; Lee \& Pee, 2013). Individuals define their postconsumption responses based on the pOCRs that they read before the purchase, which polarizes their attitudes and behavioral intentions; extremely positive OCRs cause higher post-consumption responses than moderately positive OCRs (Bhattacherjee, 2001; Herr et al., 1991; Oliver \& DeSarbo, 1998). However, if individuals have read neutral-indifferent OCRs, they develop low expectations that differ significantly from the high performance obtained. This discrepancy makes individuals establish perceptions of outcomes based on their real experience, which disconnects them from the pOCRs. Individuals determine their postconsumption responses based on a comparison between these perceptions and OCRs read before purchase (i.e., their initial expectations), as the ECT points out. Where performance 
remains the same, the more neutral-indifferent that the OCRs were, the lower will be the individuals' expectations, and the greater will be the positive disconfirmation that they experience after consumption. Thus, neutral-indifferent OCRs lead individuals to develop better post-consumption responses than moderately positive OCRs.

When performance is low, the benefits derived from the product are considered insufficient and individuals do not achieve their objectives (Olshavsky \& Miller, 1972; Zeelenberg et al., 2000). In this context, if individuals have read extremely positive OCRs before making their decisions, they develop high expectations that, subsequently, are discrepant with the poor outcomes obtained. Hence, individuals compare their low outcome perceptions with the extremely positive OCRs to define their post-consumption responses. They feel negative disconfirmation and, having received the same low performance, develop poorer post-consumption responses than those derived from moderately positive OCRs. On the other hand, if individuals read neutral-indifferent OCRs before the purchase, they develop low expectations that are consonant with the poor performance outcome subsequently obtained. Individuals adapt their outcome perceptions to neutral-indifferent OCRs, and develop their post-consumption responses in the same way. Therefore, if the performance, in the event, is the same, neutral-indifferent OCRs cause more negative post-consumption responses than moderately positive OCRs.

The following hypotheses are proposed:

H1: When performance is high (low), individuals develop better (poorer) attitude toward the firm if the OCRs read before the purchase were extremely positive or neutral-indifferent than if the OCRs were moderately positive.

H2: When performance is high (low), individuals develop greater (poorer) repurchase intentions if the OCRs read before the purchase were extremely positive or neutralindifferent than if the OCRs were moderately positive. 
H3: Positive OCRs and performance positively interact to determine individuals' postconsumption responses, namely (a) attitude toward the firm and (b) repurchase intentions.

\subsection{What is the real nature of the relationship between individuals' perception of the positivity of OCRs and their post-consumption responses?}

This section addresses the relationship between individuals' perception of the positivity of OCRs and their post-consumption responses. Individuals' perceptions about an information technology (IT) are considered as fundamental variables in seminal theories of new technology acceptance (Davis, 1989; Davis et al., 1989; Taylor \& Todd, 1995, among others). They measure the way in which certain characteristics of an IT are regarded, understood, or interpreted by individuals, determining their behavioral intentions.

Perceived positivity is defined as the degree to which individuals believe that some OCRs have positive valence. Following social judgment theory (SJT) (Sherif \& Hovland, 1961), this perception allows individuals to establish the initial expected quality of a product and serves as a judgmental anchor or a baseline level from which to evaluate performance obtained (namely, stimulus). Thus, individuals define a zone of tolerance depending on their perceived positivity, which determines how they interpret new consumption experiences and condition their post-consumption responses (Kennedy \& Thirkell, 1988; Oliver, 1980; Zeithaml et al., 1993).

In this context, some research has found that the influence of individuals' initial expected quality on their later attitudes and satisfaction follows a curvilinear pattern. For example, Vlachos et al. (2011) showed that individuals' perceived economic value of a service has a negative curvilinear effect on trust. Moreover, this trust has a positive quadratic effect on positive WOM. Similarly, Anderson and Mittal (2000) established that there is a non-linear relationship between satisfaction and retention that should be taken into account to 
avoid overestimating the impact of satisfaction (p. 115). Finally, Duverger (2013) showed that consumers assimilate OCR ratings that fall into the zone of tolerance as a valid expression of satisfaction and hotel quality. These OCRs cause individuals to book the hotel, but lower or higher ratings outside this zone lead them to reject the hotel evaluated.

In accordance with this research, it is proposed that the relationship between the perceived positivity that individuals have toward OCRs and their post-consumption responses follows curvilinear functional forms. If the performance obtained is similar to the individuals' perception of the positivity of the OCRs, the stimulus is near to the anchor and is located within the zone of tolerance. The individuals adapt their perception of outcomes to the OCRs that they read before the purchase (Yi, 1990; Yi \& La, 2003), so their perceived positivity has an assimilating effect on their post-consumption responses (Olshavsky \& Miller, 1972). This assimilating effect occurs when the difference between the perceived positivity and performance is low; that is, when the individuals read extremely positive OCRs and obtained high performance or when the individuals read neutral-indifferent OCRs and received low performance. Nevertheless, there is a point at which the performance obtained is significantly different from the OCRs, so the stimulus is located outside the zone of tolerance. In this case, individuals feel that their initial perceived positivity was misplaced and develop postconsumption responses which are inconsistent with their initial perception, the perceived positivity exerting a contrasting effect (Bridges, 1993; Lin \& Heng, 2015; Yi \& La, 2003). This effect occurs when the difference between the perceived positivity and the performance is great, that is, when the individuals read neutral-indifferent OCRs and obtained high performance or when the individuals read extremely positive OCRs and received low performance.

To sum up, this paper suggests that curvilinear functional forms between OCRs' perceived positivity and individuals' post-consumption responses should be considered. 
These forms are convex for high performance (U-shaped) and concave for low performance (inverted U-shaped) (see Figure 1). The following hypotheses are proposed:

H4: When performance is high, individuals' perceived positivity about OCRs has U-shaped relationships with their post-consumption responses, that is, (a) with their attitude toward the firm and $(b)$ with their repurchase intentions.

H5: When performance is low, individuals' perceived positivity about OCRs has inverted Ushaped relationships with their post-consumption responses, that is, (a) with their attitude toward the firm and (b) with their repurchase intentions.

(Insert Figure 1 here)

\section{Method}

An experimental study was conducted to test the above hypotheses. It did not encompass the whole consumer decision-making process but replicated several key steps, as discussed by Jones and Chen (2011), Sirakaya and Wooside (2005), and Viglia et al. (2014). Specifically, a between-subjects experiment was designed with two manipulations: positive valence intensity and performance level. Three levels were established to analyze positive valence intensity: (1) neutral-indifferent OCRs, that is, OCRs neither clearly positive nor negative, (2) moderately positive OCRs, that is, OCRs with medium positive valence, and (3) extremely positive OCRs, namely OCRs with highly positive valence. Performance was analyzed on two levels: high vs. low. As a result, the experiment was formed by six scenarios $(3 \times 2)$; that is, there were six versions of the same online social platform related to a restaurant service.

\subsection{Pretests}


Four pretests, two content analyses, and a final pilot study were conducted to develop the stimuli, to check the strength of the manipulations, and to assess the external validity of the experiment. The first pretest addressed individuals' employment of OCRs during purchase decision- making. This allowed us to refine several issues related to the design of the platform. First, it asked about the average number of OCRs that individuals usually read before making purchase decisions. Our findings established that over $85 \%$ of the respondents read between 6 and 8 reviews per business, which verified similar data obtained in previous research (Lee et al., 2008; Park \& Kim, 2008; Purnawirawan et al., 2012; Tsao et al., 2015). These findings justify our choice to include 7 OCRs per business. Second, the pretest studied the most suitable length of OCR, with the aim of being perceived as informative and not too extensive. The findings determined that each OCR should have between 3 and 5 lines, as previously established by other authors (Lee et al., 2011; Park \& Kim, 2008; Purnawirawan et al., 2012; Tsao et al., 2015). Third, the pretest defined the number of businesses that individuals evaluate within their choice set before making a decision on an online social platform. The results indicated that over $70 \%$ of the respondents usually determine a choice set of three businesses. The respondents argued that evaluating four or more options makes them feel overloaded with information, but considering only two options leads them to think that they may be ignoring optimal purchasing alternatives. Finally, the pretest asked about the individuals' trust in and familiarity with different online social platforms (e.g., TripAdvisor, Yelp, Google, Facebook, etc.). In this way, those websites that could serve as a reference to design our platform were established.

The second pretest addressed the restaurant service and consumption experience referred to in the study. Thus, this pretest defined: (1) the kind of food and restaurant that individuals prefer for a celebration and (2) the most relevant attributes that individuals consider when choosing a restaurant and evaluating its performance. An analysis content of 
the most-cited consumer reviews published on social platforms about restaurants was initially developed to define a broad list of attributes (see a similar analysis in Casalo et al., 2015). Then, two questions in this pretest requested the respondents to score the most relevant attributes included in the broad list. The findings identified three fundamental categories of attributes: service (e.g., staff, kindness, speed, etc.), food (e.g., variety of the menu, originality, etc.), and atmosphere (e.g., decoration, location, cleaning, location, etc.).

Next, a new content analysis of existing OCRs on social platforms (TripAdvisor, Yelp, etc.) was carried out with the aim of selecting reviews that could fit the scenarios with different valences (that is, neutral-indifferent, moderately positive, and extremely positive). In addition, some modifications were introduced to improve the adequacy of the manipulations (Sparks \& Browning, 2011). When the OCRs had been defined, a third pretest was carried out to refine their wording and to confirm that the individuals associated each review with the appropriate valence.

Having designed the six versions of the platform, marketing professionals and researchers took part in personal interviews to revise the preliminary version of the experimental design. They gave feedback about the clarity of instructions, checked the contents, evaluated the appropriate wording of the OCRs to operationalize the valence, and corrected mistakes in the questionnaires. Moreover, they made several suggestions to address issues that might arise during the collection of the data.

Finally, 20 volunteer readers of OCRs, who resembled the target sample, undertook a final pilot phase with the aim of testing the study in a real context. They performed the complete experiment and proposed some minor changes.

\subsection{Procedure}


The definitive design of the study was composed of seven sections that reflected experiences related to the decision-making process into which the participants were asked to place themselves. The study lasted between 30 and 40 minutes and applied storytelling techniques. ${ }^{1}$ The techniques optimized the situation description, created a personal atmosphere, and promoted the individuals' active participation, making the experience their own. Previous research has applied similar methodology and demonstrated its validity (see, for example, Bone, 1995; Söderlund, 2002).

First, a brief explanation of the study was given, and a filter question was asked to ensure that the participants were individuals who frequently used OCR platforms, such as TripAdvisor, Booking, and Yelp. Second, individuals reported their gender, age, experience as an internet user, and frequency of use of social platforms.

Third, instructions were provided describing the purchase experience. The individuals should imagine that they want to have a special celebration with their friends, and they are making plans to invite them to dinner at a Vietnamese restaurant. The individuals have made an initial evaluation of all the possible restaurants and defined their choice set with three restaurants. These restaurants are similar in price and location, so the individuals should base their final decision on other consumers' comments published on a social media platform. The individuals had seven minutes to consult the information offered by the platform and to choose a restaurant. Once they have chosen the restaurant, they should click on the "RESERVE" button. These instructions and the time limit recreate the responsibility and pressure experienced during a real purchase decision, even though the study does not require economic expenditure. Moreover, the fact that the participants can make their own purchase decision between three restaurants reflects in a better way the actual processing situation that consumers experience when reading OCRs before making a purchase. Finally, the instructions

\footnotetext{
${ }^{1}$ These techniques included: turning the participant into the protagonist, promoting gamification, explaining the beginning, development, and end of the story, and including visual and interactive effects (Lambert, 2013; Lee, 2012).
} 
explained that the success of the dinner depends on the restaurant chosen, so the individuals should read the OCRs carefully, evaluate the three restaurants, and make a well thought-out decision. Having read the guidelines, the individuals should click on a "continue" button. Thereafter, the software randomly assigned the individuals to one of the six experimental scenarios.

The fourth section opened an online social platform specialized in restaurants and bars, with OCRs about the three fictitious restaurants. Trying to make the experience as realistic as possible, the platform mimicked websites such as TripAdvisor, the largest online travel network in Europe. The three restaurants were presented with a general description, a map of the location, a photo, an overall consumer evaluation, and a link to the specific OCRs (Figure 2 shows some screenshots of the experimental design).

When the participants clicked on the name of each restaurant, they had access to the rating and content of seven OCRs. Three versions of the same platform were designed, and a different positive valence intensity was assigned to each of them. In the first version, the valence of the OCRs was extremely positive, achieving the maximum possible score (5 out of 5 points). In the second version, the valence of the OCRs was moderately positive, so they obtained 4 out of 5 points. In the third version, all the OCRs were neutral-indifferent, with ratings of 3 out of 5 (Sparks \& Browning, 2011; Zhang et al., 2010). The OCRs included in each version of the platform had the same score, that is, 5, 4 and 3 respectively; no OCR had negative valence. Thus, we did not include distortions and ensured that the participants clearly perceived the positive valence intensity in each of the three versions. Positive valence intensity was evident both in the ratings and in the content of the OCRs, which highlighted the differences between the versions of the platform. The information about the restaurants (e.g., description, location, etc.), reviewers (i.e., name, photo, age, and user profile), and some characteristics of the OCRs (e.g., time of publication, length, etc.) were kept equal across 
versions. The OCRs had a length of between three and five lines. To create the content of the OCRs, we collected user comments from real online social platforms and replaced some expressions with extremely positive, moderately positive, or neutral-indifferent words. As previously mentioned, the positive valence intensity of the OCRs was checked and revised in a pretest.

(Insert Figure 2 here)

The fifth section included the second questionnaire. It asked two questions that acted as manipulation checks about the positive valence intensity of the OCRs to guarantee the validity of the experiment. Moreover, it asked about the participants' perceptions of the OCRs (e.g., positivity, usefulness, etc.) and the purchase experience (that is, attitudes, evaluations, and intentions).

The sixth section requested the participants to imagine themselves in the consumption situation described (see a similar methodology in Aurier \& Siadou-Martin, 2007; Bone, 1995; Söderlund, 2002). Following Holbrook and Moore (1981), the description was operationalized with textual and visual elements (Alexander \& Jay, 1978). This variety of elements made it easy for participants to internalize the situation, being able to reproduce emotions, perceptions and feelings that they would experience in reality. The design of this section is consistent with the instructions given by Morales et al. (2017) in their article about experimental research. They established that, when the research goal is to study how consumers think or behave (that is, judgments, attitudes, or intentions), using artificial stimuli is legitimate and justifiable (they cited, for example, the experimental design of Kahneman and Tversky's 1979 seminal work developing prospect theory). The situation explained a consumption experience at a restaurant and detailed features of the service, food, and atmosphere (i.e., the attributes detected in the second pretest). Two versions of the same platform were designed to evaluate the effects of the second manipulation variable: high vs. 
low performance. In the first version, the restaurant decor was typically Vietnamese, the menu displayed a varied gastronomic offering from that country, and the staff were Vietnamese. It was explained that, when they finished the dinner, all the respondent's friends agreed that the choice had been a success, because the dinner had been exceptional and extremely original. In this way, the participant was expected to perceive that high performance had been obtained during the consumption. In the second version of the platform, it was explained that the restaurant chosen was similar to other restaurants in which they had previously dined, so they were not particularly impressed. The restaurant decor was simple, the menu offered few Vietnamese dishes, and the staff were not from Vietnam. When they finished dinner, all the friends agreed that, even though they had no complaints about the restaurant, the choice had not been successful, because the dinner had not been the unique experience that they had anticipated. Through this explanation, the participant perceived that low performance had been obtained during the consumption, but that it was not the restaurant's fault.

The last section of the study contained the final questionnaire that the participants had to complete about the experience described in the scenario situation. Specifically, it inquired about the performance obtained (second manipulation check), perceptions of the outcome, and post-consumption responses (that is, attitudes, evaluations, and intentions). The individuals' perceived credibility of the situation described was also addressed.

\subsection{Measures}

Table 1 presents the questions that are employed in the following analyses, which were adapted from prior research. Most items were measured on 11-point Likert scales, the lowest perception scoring 0 (strongly disagree) and the highest 10 (strongly agree). 
The questions were organized into three questionnaires. The first questionnaire asked about control variables and classifications, such as age, gender, internet experience, and frequency of use of social platforms.

The second questionnaire addressed several issues. First, it included two items to check the manipulation of positive valence intensity (Park \& Kim, 2008; Tsao et al., 2015). It also asked about the individuals' perceptions of OCRs: positivity, credibility, information quality, and usefulness (Hamby et al., 2015; Park \& Kim, 2008; Park \& Lee, 2008; Purnawiran et al., 2012; Sparks \& Browning, 2011; Zhang et al., 2010). Finally, it referred to the purchase experience and decision-making: attitude toward the restaurant, satisfaction, intention to choose the same restaurant again in the future, and so on. These questions were measured on scales developed by Eisenbeiss et al. (2014), Homburg et al. (2005), Netemeyer et al. (2005), Purnawirawan et al. (2012), Söderlund (2002), and Sparks and Browning (2011), among others.

In the third questionnaire, the participants were asked to score the performance that was obtained during the consumption experience to check that the subjects perceived the performance as it was manipulated. The questions were adapted from Bone (1995), Seddon and Kiew (1996), and Staples et al. (2002). Moreover, this questionnaire addressed the individuals' responses and evaluations derived from the entire situation described in the experiment: attitude toward the restaurant, satisfaction, and repurchase intentions, among others. These items were similar to those employed in the second questionnaire. Finally, there was a question about the individuals' perceived credibility of the situation described.

(Insert Table 1 here)

\subsection{Participants}


The participants were recruited through an online panel of a market research company, which was composed of frequent internet users. The company designed the social platform specifically for this research project and sent the link associated with the experiment to the online panel via email. By following the link, the participants were randomly assigned to 1 of the 6 experimental scenarios. Data were collected from a sample of Spanish participants in December 2018. After several depurations, 239 usable questionnaires were obtained.

The socio-demographic and user characteristics of the sample are presented in Table 2. Selection bias was controlled by determining sampling quotas based on gender and age. These quotas were established by the National Observatory for Telecommunications and the Information Society (ONTSI, 2017), one of the most important official Spanish databases. Thus, the representativeness of the sample was guaranteed.

(Insert Table 2 here)

\section{Analyses}

\subsection{Manipulation checks}

The manipulation of positive valence intensity was checked with two indicators. The first item asked the participants for the adjective phrase that best described the valence of the OCRs that they had read: 1) neutral-indifferent, 2) moderately positive, and 3) extremely positive. Those participants who did not select the option that corresponded to the scenario to which they had been assigned were considered to have given invalid answers and were eliminated. Of the sample, 239 responses correctly identified the positive valence linked to its scenario.

The second item asked the participants whether the reviews had positive valence, using a scale from 0 to 10 , with 0 representing totally disagree and 10 totally agree. A oneway analysis of variance (ANOVA) was conducted to check whether there were significant 
differences in means between the three groups: $M_{\text {neutral }}=4.15, M_{\text {moderate }}=6.61$, and $M_{\text {extreme}}=8.59$; $\mathrm{F}_{2,236}=252.722, p<.001, \mathrm{r}=0.681$. The results verified that the individuals were accurately situated within the manipulated scenario.

The manipulation of performance level was tested through t-test analyses of independent samples. There were significant differences in means between low and high performance $\left(\mathrm{M}_{\text {low performance }}=1.48\right.$, S.D.=1.587; $\mathrm{M}_{\text {high performance }}=9.25$, S.D. $=0.987 ; \mathrm{t}(237)=-$ 45.31, $\mathrm{p}<0.001, \mathrm{r}=0.16)$. Finally, the six experimental scenarios were assessed in terms of the credibility of the situation described, on the basis of 2 items measured on an 11-point Likert scale. The entire experimental study appeared to be reasonably credible, with means varying between 6.78 and 7.70 .

Overall, it can be stated that the experimental design was successful, and the procedure was correctly developed.

\subsection{The influence of positive valence intensity on individuals' post-consumption responses}

Cronbach's alphas for the individuals' post-consumption responses were calculated: they were 0.988 for attitude toward the firm and 0.965 for repurchase intentions, exceeding the recommended limit of 0.7 in the literature (Nunnally, 1978). Then, mean values were estimated for the analyses.

A two-way between-groups analysis of variance (ANOVA) was conducted to test the main effects of the manipulated variables and their interaction effects. The results are presented in Table 3, and the means in Table 4. First, the results demonstrate that the main effects of positive valence intensity are not statistically significant for individuals' attitude toward the firm [F (2, $233)=0.526 ; p=0.591]$ and repurchase intentions $[F(2,233)=1.673 ; p=0.190]$. Second, the main effects of performance level are verified, both for attitude toward the firm $[\mathrm{F}(1,233)=$ 1021.243, $\mathrm{p}=0.000]$ and repurchase intentions $[\mathrm{F}(1,233)=1137.141, \mathrm{p}=0.000]$. Effect sizes 
were calculated using eta squared: 0.814 for attitude, and 0.830 for repurchase intentions. Based on the guidelines proposed by Cohen (1988, pp. 284-287), the strength of these effects are large $(\geq 0.14)$. Third, the results revealed significant interaction effects between the two manipulated variables for the two dependent variables: attitude toward the firm $[\mathrm{F}(2,233)=$ 8.059, $\mathrm{p}=0.000]$ and repurchase intentions $[\mathrm{F}(2,233)=12.977, \mathrm{p}=0.000]$. Effect sizes were moderate ( $\geq 0.06)$ : 0.065 for attitude toward the firm, and 0.100 for repurchase intentions.

(Insert Tables 3 and 4 here)

An examination of the marginal means shows that the joint effect of positive valence intensity and performance level on individuals' post-consumption responses is not increasing and linear but shows different trends (see Table 4). When performance is high, the results demonstrate that individuals who read extremely positive OCRs show significantly better responses than those linked to individuals who read moderately positive OCRs (8.74 vs. 8.06; $\mathrm{p}<0.05$ for attitude and 8.58 vs. $7.80 ; \mathrm{p}<0.1$ for repurchase intentions). Nevertheless, this increasing trend is not observed if neutral-indifferent and moderately positive OCRs are compared. In that case, individuals who read neutral-indifferent OCRs and obtained high performance present better attitudes and greater repurchase intentions than those individuals who read moderately positive OCRs. In other words, when performance is high, extremely positive OCRs and neutral-indifferent OCRs generate better post-consumption responses than moderately positive OCRs.

When performance is low, the results demonstrate that individuals who read extremely positive OCRs show post-consumption responses that are significantly worse than those experienced by individuals who read moderately positive OCRs $(2.11$ vs. 3.18 , p $<0.05$ for attitude and 0.91 vs. $2.49, \mathrm{p}<0.01$ for repurchase intentions). On the other hand, if individuals who read neutral OCRs are compared with individuals who read moderately positive OCRs, it can be observed that the former show poorer attitudes and lower repurchase intentions than the 
latter. In other words, when performance is low, extremely positive and neutral-indifferent OCRs drive individuals to develop poorer attitudes toward the firm and lower repurchase intentions than moderately positive OCRs.

Therefore, the findings support $\mathrm{H} 1, \mathrm{H} 2$ and $\mathrm{H} 3$.

\subsection{The relationship between individuals' perceived positivity and their post-consumption responses}

In this section the functions that reflect the relationship between individuals' perceived positivity and their post-consumption responses are estimated. To do so, individuals' perceptions, attitudes, and behavioral intentions measured during the experiment are tested. The sample was split into two groups according to performance: 121 answers were related to low performance and 118 answers to high performance. The estimations were carried out with STATA, 14.0. Because our main independent variable is time-invariant, we conducted cross-sectional analyses of the data by testing ordinary least squares (OLS) robust estimations and non-linear least squares (NLS) robust estimations, which controlled for potential problems of heteroscedasticity. The methodology proposed by Haans et al. (2016) was applied to identify and analyze U-shaped relationships.

Tables 5 and 6 present the estimation models showing the influence of individuals' perception of the positive valence of OCRs on their post-consumption responses for high and low performance, respectively. The control variables (sex, age, and internet experience), the independent variable (pOCRs), and the quadratic term of the independent variable (pOCRs squared) are studied. Models 1 and 5 are basic models which introduce all the control variables and omit the variables relevant to the testing of the hypotheses. Models 2 and 6 show the relationship between the pOCRs and the endogenous variable through analyses of linear functional forms. Models 3 and 7 introduce the quadratic term of the independent 
variable, which is necessary to test $\mathrm{H} 4$ and H5. Finally, Models 4 and 8 add the cubic term, which may support the appropriateness of the S-shaped relationship rather than the inverted U-shaped relationship.

The adequacy of these models was analyzed using the Wald $\chi 2$ test. This test is applied because the likelihood ratio test is not adequate in robust settings and non-likelihood estimations. It checks that the independent variables included in a model are not jointly equal to zero and therefore should be included. This test compares nested models and determines which is the best estimation. The results are shown in the last rows of Tables 5 and 6 . Regarding attitude toward the firm, Model 3 is significantly better than Models 1 and 2, while Model 4 is better than Models 1 and 2, but worse than Model 3. Regarding repurchase intentions, Model 7 is significantly better than Models 5 and 6, while Model 8 is better than Models 5 and 6, but worse than Model 7. In other words, Models 3 and 7, which explore the quadratic functional form, have the best explanatory power for analyzing the relationship between perceived positivity and post-consumption responses.

(Insert Tables 5 and 6 here)

The results of the regressions in Models 3 and 7 include a significant quadratic term, which indicates U-shaped relationships. Nevertheless, it should be noted that a significant quadratic term only provides the necessary condition for the existence of a U-shaped relationship and not a sufficient condition. Sufficient conditions are described by Lind and Mehlum's (2010) three-step procedure and the U-test. In this way, this procedure was tested for the two endogenous variables and for the two levels of performance, verifying all the conditions (see Table 7).

In the first step, the quadratic terms are significant and of the expected sign, as shown above in the results of the regressions. In the second, the slopes are significantly steep at both 
ends of the data range, ${ }^{2} \mathrm{XL}$ at the low end of the X-range and $\mathrm{XH}$ at the high end. For low performance, $\mathrm{XL}$ is positive and significant while $\mathrm{XH}$ is negative and significant. For high performance, $\mathrm{XL}$ is negative and significant while $\mathrm{XH}$ is positive and significant. In the third step, turning points are located within the data range (between 0 and 10). This condition is also verified by estimating the 95 percent confidence intervals using the Fieller method (Fieller, 1954) to account for the finite sample bias and to correct for biases caused by departure from normality. Finally, U-tests verify the significance of the relationships.

\section{(Insert Table 7 here)}

For high performance, the results of Models 3 and 7 confirm the U-shaped relationships between individuals' perceived positivity and their post-consumption responses (see Table 5). This perception has a negative and significant linear influence on individuals' attitude toward the firm $\left(\beta_{1}=-0.477, \mathrm{p}<0.001\right)$ and repurchase intentions $\left(\beta_{1}=-0.349, \mathrm{p}<0.001\right)$. Moreover, the findings support the positive and significant influence of the quadratic term on attitude toward the firm $\left(\beta_{2}=0.048, \mathrm{p}<0.001\right)$ and repurchase intentions $\left(\beta_{2}=0.038, \mathrm{p}<0.001\right)$. Consequently, $\mathrm{H} 4 \mathrm{a}$ and $\mathrm{H} 4 \mathrm{~b}$ are supported.

For low performance, the results of Models 3 and 7 verify the inverted U-shaped relationships between the individuals' perceived positivity and post-consumption responses (see Table 6). The independent variable has a positive and significant linear influence on the individual's attitude toward the firm $\left(\beta_{1}=0.989, \mathrm{p}<0.001\right)$ and repurchase intentions $\left(\beta_{1}=1.121, \mathrm{p}<0.001\right)$. Moreover, these results confirm a negative and significant influence of the quadratic term on attitude toward the firm $\left(\beta_{2}=-0.089, \mathrm{p}<0.001\right)$ and repurchase intentions $\left(\beta_{2}=-0.106, \mathrm{p}<0.001\right) . \mathrm{H} 5 \mathrm{a}$ and $\mathrm{H} 5 \mathrm{~b}$ are verified.

To increase confidence in the findings of our empirical analysis, several additional analyses were conducted as robustness checks to confirm the quadratic relationships. These

\footnotetext{
${ }^{2}$ If only one slope is significant, the relationship might be one half of a U-shape, which can be fitted more parsimoniously by a logarithmic or exponential function (Haans et al., 2016).
} 
analyses confirm that, when performance is high, the perceived positivity maintains a Ushaped relationship with the post-consumption responses. On the contrary, when performance is low, the perceived positivity maintains an inverted U-shaped relationship with the postconsumption responses.

\section{Contributions, implications, and future lines}

\subsection{Academic contributions}

Although the research on OCRs is broad and has investigated a wide variety of topics, several gaps remain. This paper makes two notable academic contributions.

First, it demonstrates the importance of analyzing the influence of pOCRs after consumption, when individuals are better able to evaluate the outcomes obtained. Generally, previous research has assumed that the main role of pOCRs is played before individuals make their purchase decisions, so it has addressed the immediate influence of pOCRs on sales and purchase intentions and applied a transactional perspective. Nevertheless, it has ignored the role of pOCRs after the consumers have made their decisions and obtained the performance of the chosen product. In an attempt to deal with this issue, the present paper argues that the influence of pOCRs is maintained during the later stages of the decision-making process, so it focuses on individuals' responses after the consumption. At this stage, individuals are able to compare their initial expectations with the performance obtained, evaluate their experience and develop their responses. The findings demonstrate that pOCRs are a key element of the comparison, because they determine the initial expectations and act as a judgmental anchor to evaluate the outcomes obtained. Consequently, pOCRs and performance have a joint effect on post-consumption responses. Future research should not focus on the immediate effect of pOCRs on sales but should address how they influence the customer-firm relationship in the long term, analyzing variables such as customer engagement. 
Second, contrary to the belief established in prior research that pOCRs always have positive and linear influences on consumer behavior, this study demonstrates that, when performance comes into play, pOCRs have different influences on individuals' postconsumption responses. In contrast to previous research, this paper applies a twofold approach that analyzes positive valence intensity and individuals' perceived positivity. The findings show that pOCRs do not exert a consistent positive influence on post-consumption responses; their influence varies in direction and intensity depending on whether the performance was high or low and how positive the OCRs were. Moreover, the findings demonstrate that perceived positivity acts in a similar way to other service perceptions, following U-shaped functional forms. These forms are concave for low performance (inverted U-shaped) and convex for high performance (U-shaped). Detecting these functional forms is essential in studying consumer behavior and to anticipating the potential consequences of pOCRs.

\subsection{Managerial implications}

This paper highlights three managerial implications.

In social media, firms should avoid the application of a transactional approach dedicated to climbing positions in OCR rankings. This transactional approach means that firms seek only the achievement of a higher position in rankings and an increase in financial returns due to the influence of OCRs. This approach takes a short-term view and ignores what happens after the purchase. Beyond this approach, this study suggests that firms should design their social media practices to try to achieve the greatest consistency between OCRs and performance. Moreover, they should consider the whole decision-making process and address the influence of OCRs on individuals' attitude toward the firm and intentions after consumption. OCRs are important not only for explaining purchase decisions but also for 
studying post-consumption relationships. Therefore, firms should beware of projecting an idealized image of the product and the firm on social media, which may be profitable in the short term but will erode consumer trust in the long term.

Firms should also manage positive OCRs. To date, most strategies about social platforms have focused on determining, first, how to avoid, delete, or hide negative OCRs and, second, how to promote the positive effects of pOCRs, identifying influencers and encouraging advocates (Chen \& Xie, 2008). These strategies take for granted that pOCRs always provide positive consequences, without any further actions from the firm. Nevertheless, this study demonstrates that pOCRs can be detrimental to the firm, so they should also be managed appropriately. The firm should explain misleading pOCRs, clarify experiences that are unrepresentative or difficult to replicate, and compensate customers who expected too much.

Firms should understand that extremely positive OCRs can be counterproductive for improving consumers' post-consumption responses. They should ensure that extremely positive OCRs about their products posted on social media should not only be true but should also be matched by performance. Extremely positive OCRs will result in individuals making more positive purchase decisions. Nevertheless, if performance is low, extremely positive OCRs will have the opposite effect and lead individuals to develop negative postconsumption responses. Firms should be aware that it is not only negative OCRs that are dangerous; extremely positive OCRs may result in an immediate transaction but can be detrimental to the achievement of positioning and good reputation. Very positive can be as damaging as very negative. This finding contradicts the traditional belief that positive OCRs always have positive consequences.

\subsection{Limitations and future lines}


Our study has some limitations that should be taken into account in future research. First, this research collected data from questionnaires included in an experimental design that reproduced different stages of the decision-making process. Psychological variables, such as individuals' attitudes and behavioral intentions, were analyzed. Nevertheless, the influence of pOCRs on objective responses was not tested. In future research it would be interesting to observe and collect longitudinal information about individuals' behavior during a real experience on an OCR platform, the consumption of the product, and their objective responses after consumption. In this way, it will be possible to consider different stages of the purchase process and to address the evolution of individuals' behavior.

Second, this paper studied the influence of pOCRs read before the purchase decision but did not test the influence of OCRs that individuals read after purchasing the product. In future research, it would be interesting to analyze the influence of OCRs that individuals read at different stages. In this case, both positive and negative OCRs should be tested, because they may modify individuals' cognition about the products chosen and determine their consumption perceptions. Moreover, the moderating effect of other OCR aspects, such as sequence, volume, or product type, should be addressed.

Finally, it should be taken into account that this study includes the influence of positive valence but ignores other exogenous variables, such as social norms, price, consumers' capacity to evaluate, experience in the use of these platforms, and personality. These variables may affect the individuals and interact with the positive valence during different stages of the decision-making process, so they should be studied in future research.

\section{Conclusions}

The present study explores the relationship between pOCRs and individuals' postconsumption responses. Specifically, it analyzes attitude toward the firm and repurchase 
intentions. Our findings demonstrate that, following the purchase, positive valence intensity interacts with performance to determine post-consumption responses, causing effects with different directions and intensities. Similarly, individuals' perceived positivity follows curvilinear functional forms that are concave for low performance (inverted U-shaped) and convex for high performance (U-shaped). Overall, this study clarifies that the influence of pOCRs extends beyond the purchase decision, so future research should examine what happens after the consumption experience.

\section{References}

Aaker, J., Drolet, A., \& Griffin, D. (2008). Recalling recall bias. Journal of Consumer Research, 35, 268-278.

Abelson, R.P. (1995). Attitude extremity. In R.E. Petty, \& J.A. Krosnick (Eds.), Attitude strength: Antecedents and consequences (pp. 25-42). Mahwah, NJ: Lawrence Erlbaum.

Alexander, C.S., \& Jay, B.H. (1978). The use of vignettes in survey research. Public Opinion Quarterly, 42(1), 93-104.

Anderson, E., \& Mittal, V. (2000). Strengthening the satisfaction-profit chain. Journal of Service Research, 3(2), 107-120.

Aurier, P., \& Siadou-Martin, B. (2007). Perceived justice and consumption experience evaluations. A qualitative and experimental investigation. International Journal of Service Industry Management, 18(5), 450-471.

Beerli-Santana, A., \& Martín-Santana, J. (2017). How does confirmation of motivations influence on the pre- and post-visit change of image of a destination? European Journal of Management and Business Economics, 26(7), 238-251.

Bendapudi, N., \& Leone, R.P. (2003). Psychological implications of customer participation in co-production. Journal of Marketing, 67(January), 14-28.

Bhattacherjee, A. (2001). Understanding information systems continuance: An expectation confirmation model. MIS Quarterly, 25(3), 351-370.

Blackwell, R., Miniard, P., \& Engel, J.F. (2005). Consumer behavior. $5^{\text {a }}$ ed. Florida, Dryden Press.

Bone, P.F. (1995). Word-of-mouth effects on short-term and long-term product judgments. Journal of Business Research, 32, 213-223.

Bridges, E. (1993). Service attributes: expectations and judgments. Psychology and Marketing, 10(3), 185-197.

BrightLocal (2017). Local Consumer Review Survey, Available at: https://www.brightlocal.com/learn/local-consumer-review-survey/ 
Bronner, A.E., \& de Hoog, R. (2011). Vacationers and eWOM: who posts, and why, where, and what? Journal of Travel Research, 50(1), 15-26.

Buunk, A.P., \& Gibbons, F.X. (2007). Social comparison: The end of a theory and the emergence of a field. Organizational Behavior and Human Decision Processes, 102, 3-21.

Cadotte, E.R., Woodruff, R.B., \& Jenkins, R.L. (1987). Expectations and norms in models of consumer satisfaction. Journal of Marketing Research, 19(4), 491-504.

Casalo, L., Flavián, C., Guinaliu, M., \& Ekinci, Y. (2015). Avoiding the dark side of positive online consumer reviews: Enhancing reviews' usefulness for high risk-averse travelers.

Journal of Business Research, 68(9), 1829-1835.

Chan, H., \& Cui, S. (2011). The contrasting effects of negative word of mouth in the postconsumption stage. Journal of Consumer Psychology, 21, 324-337.

Chang, E.-C., Lv. Y., Chou, T.-J., He, Q., \& Song, Z. (2014). Now or later: Delay's effects on post-consumption emotions and consumer loyalty. Journal of Business Research, 67, $1368-1375$.

Chen, Y., \& Xie, J. (2008). Online consumer review: word of mouth as a new element of marketing communication mix. Management Science, 54, 447-491.

Chua, B.-L., Lee, S., \& Han, H. (2017). Consequences of cruise line involvement: a comparison of first-time and repeat passengers. International Journal of Contemporary Hospitality Management, 29(6), 1658-1683.

Cohen, J.W. (1988). Statistical power analysis for the behavioral sciences $\left(2^{\text {nd }}\right.$ edn). Hillsdale, NJ: Lawrence Erlbaum Associates.

Cowley, E. (2014). Consumers telling consumption stories: word-of-mouth and retrospective evaluations. Journal of Business Research, 67, 1522-1529.

Davis, F.D. (1989). Perceived usefulness, perceived ease of use and user acceptance of information technology. MIS Quarterly, 19(2), 189-211.

Davis, F.D., Bagozzi, R.P., \& Warshaw, P.R. (1989). User acceptance of computer technology: a comparison of two theoretical models. Management Science, 35, 982-1003.

Dellarocas, C., Zhang, X., \& Awd, N. (2007). Exploring the value of online product reviews in forecasting sale: the case of motion pictures. Journal of Interactive Marketing, 21(4), 2345 .

Dias, L., \& Lobel, M. (1997). Social comparison in medically high-risk pregnant women. Journal of Applied Social Psychology, 27, 1629-1649.

Duan, W., Gu, B., \& Whinston, A.B. (2008). The dynamics of online WOM and product sales- An empirical investigation of the movie industry. Journal of Retailing, 84(2), 233-242.

Duverger, P. (2013). Curvilinear effects of user-generated content on hotels' market share: a dynamic panel-data analysis. Journal of Travel Research, 52, 465-478.

Eagly, A.H., \& Chaiken, S. (1993). The psychology of attitudes. Fort Worth, TX: Harcourt Brace College Publishers.

Eisenbeiss, M., CorneliBen, M., Backhaus, K., \& Hoyer, W. (2014). Nonlinear and asymmetric returns on customer satisfaction: do they vary across situations and consumers? Journal of Academy of Marketing Science, 42, 242-263. 
Engel, J., Kollat, D., \& Blackwell, R. (1968). Consumer behavior. 1st edition. New York: Holt, Rinehart and Winston.

Fieller, E.C. (1954). Some problems in interval estimation. Journal of the Royal Statistical Society, Series B (Methodological), 16(2), 175-185.

Floyd, K., Freling, R., Alhoqail, S., Young Cho, H., \& Freling, T. (2014). How online product reviews affect retail sales: a meta-analysis. Journal of Retailing, 90(2), 217-232.

Forman, C., Ghose, A., \& Wiesenfield, B. (2008). Examining the relationship between reviews and sales: the role of reviewer identity disclosure in electronic markets. Information Systems Research, 19(3), 291-313.

Grace, D., \& O'Cass, A. (2001). Examining service experiences and post-consumption evaluations. Journal of Services Marketing, 18(6), 450-461.

Gilly, M.C., Graham, J.L., Wolfinbarger, M.F., \& Yale, L.J. (1998). A dyadic study of interpersonal information search. Journal of Academy of Marketing Science, 26, 83-100.

Haans, R.F.J., Pieters, C., \& He, Z.-L. (2016). Thinking about U: Theorizing and testing Uand inverted U-shaped relationships in strategy research. Strategic Management Journal, 37(7), 1177-1195.

Hamby, A., Danisloski, K., \& Brinberg, D. (2015). How consumer reviews persuade through narratives. Journal of Business Research, 68, 1242-1250.

Helgeson, V.S., \& Taylor, S.E. (1993). Social comparison and adjustment among cardiac patients. Journal of Applied Social Psychology, 23, 1171-1195.

Heimbach, I., \& Hinz, O. (2016). The impact of content sentiment and emotionality on content virality. International Journal of Research in Marketing, 33(3), 695-701.

Holbrook, M.B., \& Moore, W.L. (1981). Feature interactions in consumer judgments of verbal versus pictorial presentations. Journal of Consumer Research, June, 103-113.

Homburg, C., Koschate, N., \& Hoyer, W.D. (2005). Do satisfied customers really pay more? A study of the relationship between customer satisfaction and willingness to pay. Journal of Marketing, 69, 84-96.

Hosany, S., \& Prayag, G. (2013). Patterns of tourists' emotional responses, satisfaction, and intention to recommend. Journal of Business Research, 66, 730-737.

$\mathrm{Hu}$, Y., \& Li, X. (2011). Context-dependent product evaluations: a empirical analysis of Internet book reviews. Journal of Interactive Marketing, 25, 123-133.

Jang, S., \& Namkung, Y. (2009). Perceived quality, emotions, and behavioral intentions: Application of an extended Mehrabian-Russell model to restaurants. Journal of Business Research, 62, 451-460.

Jones, P., \& Chen, M.M. (2011). Factors determining hotel selection: online behavior by leisure travelers. Tour Hospitality Research, 11, 83-95.

Kahneman, D., \& Tversky (1979). Prospect theory: an analysis of decision under risk. Econometrica, 47(2), 263-292.

Kennedy, J.R., \& Thirkell, P.C. (1988). An extended perspective on the antecedents of satisfaction. Journal of Consumer Satisfaction, Dissatisfaction and Complaining Behavior, 1, $2-9$. 
Kim, S., Chung, J.-E., \& Suh, Y. (2016). Multiple reference effects on restaurant evaluations: a cross-cultural study. International Journal of Contemporary Hospitality Management, 28(7), 1441.1466.

Koo, D.-M. (2015). The strength of no tie relationship in an online recommendation. European Journal of Marketing, 49(7/8), 1163-1183.

Kostyra, D.S., Reiner, J., Natter, M., \& Klapper, D. (2016). Decomposing the effects of online customer reviews on brand, price, and product attributes. International Journal of Research in Marketing, 33(1), 11-26.

Lambert, J. (2013). Digital storytelling: capturing lives, creating community. Berkeley, CA: Digital Diner Press.

Lee, D. (2012). Powerful storytelling techniques. Association for Talent Development.

Lee, J., \& Pee, L.G. (2013). Reading consumer reviews to confirm my expectations: the accelerated impact of confirmation under extreme review tones. Pacific Asia Conference on Information Systems (PACIS) Proceedings, 76. Available in: http://aisel.aisnet.org/cgi/viewcontent.cgi?article=1076\&context=pacis2013 (12/19/2017).

Lee, M., \& Youn, S. (2009). Electronic word of mouth (eWOM): How eWOM platforms influence consumer product judgment. International Journal of Advertising: The Quarterly Review of Marketing Communications, 28(3), 473-499.

Lee, J., Park, D.-H., \& Han, I. (2008). The effect of negative online consumer reviews on product attitude: an information processing view. Electronic Commerce Research and Applications, 7, 341-352.

Lee, J., Lee, J., \& Shin, H. (2011). The long tail or the short tail: the category-specific impact of eWOM on sales distribution. Decision Support Systems, 51(3), 466-479.

Lin, Z., \& Heng, C.-S. (2015). The paradoxes of word of mouth in electronic commerce. Journal of Management Information Systems, 32(4), 246-284.

Lin, C.-P., Tsai, Y.H., \& Chiu, C.-K. (2009). Modeling customer loyalty from an integrative perspective of self-determination theory and expectation-confirmation theory. Journal of Business Psychology, 24, 315-326.

Lind, J., \& Mehlum, H. (2010). With or without you? The appropriate test for a u-shaped relationship. Oxford Bulletin of Economics and Statistics, 72(1), 109-118.

Liu, Y. (2006). Word of mouth for movies: Its dynamics and impact on box office revenue. Journal of Marketing, 70, 74-89.

Loftus, E. (1975). Leading questions and the eyewitness report. Cognitive Psychology, 7 , 560-572.

Loftus, E. (1979). Reactions to blatantly contradictory information. Memory \& Cognition, 7, 368-374,

Moe, W.W., \& Trusov, M. (2011). The value of social dynamics in online product ratings forums. Journal of Marketing Research, 48(3), 444-456.

Morales, A.C., Amir, O., \& Lee, L. (2017). Keeping it real experimental, researchUnderstanding when, where, and how to enhance realism and measure consumer behavior. Journal of Consumer Research, 44(2), 465-476.

Mudambi, S.M., \& Schuff, D. (2010). What makes a helpful review? A study of customer reviews on Amazon.com. MIS Quarterly, 34(1), 185-200. 
Netemeyer, R.G., Maxham, J.G., \& Pullig, C. (2005). Conflicts in the work-family interface: links to job stress, customer service employee performance, and customer purchase intent. Journal of Marketing, 69, 130-143.

Nicosia, F.M. (1966). Consumer decision process: marketing and advertising complications. Prentice Hall, Englewood Cliffs, New York.

Nunnally, J. (1978). Psychometric theory. McGraw-Hill, New York.

Oghuma, A.P., Libaque-Saenz, C.F., \& Chang, Y. (2016). An expectation-confirmation model of continuance intention to use mobile instant messaging. Telematics and Informatics, $33,34-47$.

Oliver, R.L. (1977). Effect of expectation and disconfirmation on post-exposure product evaluations: an alternative interpretation. Journal of Applied Psychology, 62(4), 480-486.

Oliver, R.L. (1980). A cognitive model of the antecedents and consequences of satisfaction decisions. Journal of Marketing Research, 17(4), 46-49.

Oliver, R.L., \& DeSarbo, W.S. (1998). Response Determinants in Satisfaction Judgments. Journal of Consumer Research, 14(2), 495-507.

Olshavsky, R.W., \& Miller, J.A. (1972). Consumer expectations, product performance, and perceived product quality. Journal of Marketing Research, 9, 19-21

ONTSI (2017). Perfil sociodemografico de los internautas. Analisis de datos INE 2017. Observatorio Nacional de las telecomunicaciones y de la sociedad de la información. Available https://www.ontsi.red.es/ontsi/sites/ontsi/files/Perfil\%20sociodemogr\%C3\%A1fico\%20de\%2 0los\%20internautas\%202017.pdf

Pan, L.-Y., \& Chiou, J.-S. (2011). How much can you trust online information? Cues for perceived trustworthiness of consumer-generated online information. Journal of Interactive Marketing, 25(2), 67-74.

Pansari, A., \& Kumar, V. (2017). Customer engagement: the construct, antecedents, and consequences. Journal of the Academy Marketing Science, 45(3), 294-311.

Park, D., \& Kim, S. (2008). The effects of consumer knowledge on message processing of electronic word-of-mouth via online consumer reviews. Electronic Commerce Research and Applications, 7(4), 399-410.

Park, D., \& Lee, J. (2008). eWOM overload and its effect on consumer behavioral intention depending on consumer involvement. Electronic Commerce Research and Applications, 7(4), 386-398.

Park, C., \& Lee, T. (2009). Information direction, website reputation and eWOM effect: a moderating role of product type. Journal of Business Research, 62(1), 61-67.

Park, S., \& Nicolau, J.L. (2015). Asymmetric effects of online consumer review. Annals of Tourism Research, 50, 67-83.

Pavlou, P., \& Dimoka, A. (2006). The nature and role of feedback text comments in online marketplace: implications for trust building, price premiums, and seller differentiation. Information Systems Research, 17(4), 392-414.

Purnawirawan, N., De Pelsmacker, P., \& Dens, N. (2012). Balance and sequence in online reviews: how perceived usefulness affects attitudes and intentions. Journal of Interactive Marketing, 26(4), 244-255. 
Schindler, R.M., \& Bickart, B. (2005). Published word of mouth: Referable, consumergenerated information on the Internet. In C. P. Haugtvedt, K. A. Machleit, \& R. F. Yalch (Eds.), Online consumer psychology: Understanding and influencing consumer behavior in the virtual world (pp. 35-61). Mahwah, NJ: Lawrence Erlbaum.

Seddon, P., \& Kiew, M.Y. (1996). A partial test and development of the DeLone and McLean model of IS Success. Australian Journal of Information Systems, 4, 90-109.

Sherif, M., \& Hovland, C.I. (1961). Social judgment: assimilation and contrast effects in communication and attitude change. Oxford, England, Yale University Press.

Shi, X., \& Liao, Z. (2017). Online consumer review and group-buying participation: the mediating effects of consumer beliefs. Telematics and Informatics, 34, 605-617.

Sirakaya, E., \& Wooside, A.G. (2005). Building and testing theories of decision making by travelers. Tourism Management, 26(6), 815-832.

Söderlund, M. (2002). Customer familiarity and its effects on satisfaction and behavioral intentions. Pyschology and Marketing, 19, 861-879.

Sparks, B., \& Browning, V. (2011). The impact of online reviews on hotel booking intentions and trust. Tourism Management, 32(6), 1310-1323.

Staples, S., Wong, I., \& Seddon, P.B. (2002). Having expectations of information systems benefits: does it really matter? Information \& Management, 40, 115-131.

Tang, T., Fang, E., \& Wang (2014). Is neutral really neutral? The effects of neutral usergenerated content on product sales. Journal of Marketing, 78, 41-58.

Taylor, S., \& Todd, P.A. (1995). Understanding information technology usage: A test of competing models. Information Systems Research, 6(2), 144-176.

Triantafillidou, A., \& Siomkos, G. (2014). Consumption experience outcomes: satisfaction, nostalgia intensity, word-of-mouth communication and behavioral intentions. Journal of Consumer Marketing, 31(6/7), 526-540.

Tsao, W.-H., Hsieh, M.-T., Shih, L.-W., \& Lin, T.M.Y. (2015). Compliance with eWOM: The influence of hotel reviews on booking intention from the perspective of consumer conformity. International Journal of Hospitality Management, 46, 99-111.

Tse, D.K., \& Wilton, P.C. (1988). Models of consumer satisfaction formation: an extension. Journal of Marketing Research, XXV, 204-212.

Viglia, G., Furlan, R., \& Ladrón-de-Guevara, A. (2014). Please, talk about it! When hotel popularity boosts preferences. International Journal of Hospitality Management, 42, 155164.

Vlachos, P.A., Pramatari, K., \& Vrechopolos, A. (2011). Too much of a good thing: curvilinear effects of service of service evaluation constructs and the mediating role of trust. Journal of Service Marketing, 25(6), 440-450.

Walsh, G., Shiu, E., Hassan, L.M., Michaelidou, N., \& Beatty, S. (2011). Emotions, storeenvironmental cues, store-choice criteria, and marketing outcomes. Journal of Business Research, 64, 737-744.

Wang, F., Liu, X., \& Fang, E. (2015). User reviews variance, critic reviews variance, and product sales: an exploration of customer breadth and depth effects. Journal of Retailing, 91(3), 372-389. 
Wirtz, J., \& Chew, P. (2002). The effects of incentives deal proneness, satisfaction and tie strength on word-of-mouth behaviour. International Journal of Service Industry Management, 13(2), 141-162.

$\mathrm{Xu}, \mathrm{X}$. (2019). Examining an asymmetric effect between online customer reviews emphasis and overall satisfaction determinants. Journal of Business Research, in press.

Xu, J., \& Schwartz, N. (2009). Do we really need a reason to indulge? Journal of Marketing Research, 46, 25-36.

Ye, Q., Law, R., Gu, B., \& Chen, W. (2011). The influence of user-generated content on traveler behavior: An empirical investigation on the effects of e-word-of-mouth to hotel online bookings. Computers in Human Behavior, 27, 634-639.

Yi, Y. (1990). A critical review of consumer satisfaction, in Valerie, A. Zeithaml (ed.), Review of Marketing. Chicago: American Marketing Association, 68-123.

Yi, Y., \& La, S. (2003). The moderating role of confidence in expectations and the asymmetric influence of disconfirmation on customer satisfaction. The Services Industries Journal, 23(5), 20-47.

Yim, C.K., Chan, K.W., \& Hung, K. (2007). Multiple reference effects in service evaluations: roles of alternative attractiveness and self-image congruity. Journal of Retailing, 83(1), 147157.

Yoo, K.H., \& Gretzel, U. (2008). What motivates consumers to write online travel reviews? Information Technology \& Tourism, 10(4), 283-295.

Zeelenberg, M., \& Pieters, R. (1999). Comparing service delivery to what might have been behavioral responses to regret and disappointment. Journal of Service Research, 2(1), 86-97.

Zeelenberg, M., van Dijk, W.W., Manstead, A.S.R., \& van der Plight, J. (2000). On bad decisions and disconfirmed expectancies: the psychology of regret and disappointment. Cognition and Emotion, 14, 521-541.

Zeithaml, V.A, Berry, L.L., \& Parasuraman, A. (1993). The nature and determinants of customer expectations of service. Journal of the Academy of Marketing Science, 21(1), 1-12.

Zhang, J.Q., Craciun, G., \& Shin, D. (2010). When does electronic word-of-mouth matter? A study of consumer product reviews. Journal of Business Research, 63(12), 1336-41. 
Table 1

Questions in the study.

FACTOR (source)

\section{INDICATORS}

First questionnaire, variables of control and classification

AGE AND GENDER

How long have you been an Internet user (for any purpose, including surfing

websites, email, Facebook, chats, etc.)?

INTERNET EXPERIENCE

Answers from "less than six months" (1) to

"eight years or more" (7)

INTENSITY OF USE OF THE INTERNET

(per week)

FREQUENCY OF USE OF SOCIAL

PLATFORMS

Second questionnaire, filled in after the participants have made their purchase decision (11-point Likert scales)

POSITIVE VALENCE INTENSITY

Manipulation check 1A

Manipulation check 1B

(Park \& Kim, 2008; Tsao et al., 2015)

\section{PERCEIVED POSITIVITY}

(Hamby et al., 2015; Park \& Kim, 2008; Park \& Lee, 2008; Sparks \& Browning, 2011; Zhang et al., 2010)

Third questionnaire, filled in after describing the consumption results (11-point Likert scales)

\section{PERFORMANCE}

Manipulation check 2

(Lin et al., 2009; Söderlund, 2002)

\section{ATTITUDE TOWARD THE FIRM}

(Purnawirawan et al., 2012)

\section{REPURCHASE INTENTIONS}

(Eisenbeiss et al., 2014; Homburg et al., 2005; Söderlund, 2002; Zeelenberg \& Pieters, 1999)

\section{PERCEIVED CREDIBILITY}

(Bendapudi \& Leone, 2003; Sparks \& Browning, 2011)
I think that the performance of the restaurant chosen has been ...

$$
\text { Answers from "very low" (0) to "very high" (10) }
$$

After the experience described, my attitude toward the restaurant is ...

... good

... positive

...favorable

Answers from "totally disagree" (0) to "totally agree" (10)

After the experience described, if in the future I had the opportunity ...

... It is likely that I would book this restaurant again

... It is probable that I would select this restaurant again

... I would be willing to make the same purchase

Answers from "totally disagree" (0) to "totally agree" (10)

The situation described in the study is...

... realistic

...very believable

Answers from "totally disagree" (0) to "totally agree" (10) 
Table 2

Socio-demographic and user characteristics of participants.

\begin{tabular}{|c|c|c|c|c|c|}
\hline & ITEMS & \begin{tabular}{|c} 
ABSOLUTELY \\
LOW PERF. \\
\end{tabular} & \begin{tabular}{|c} 
\% SAMPLE \\
LOW \\
PERF. \\
\end{tabular} & $\begin{array}{c}\text { ABSOLUTELY } \\
\text { HIGH PERF. }\end{array}$ & $\begin{array}{c}\text { \% SAMPLE } \\
\text { HIGH } \\
\text { PERF. } \\
\end{array}$ \\
\hline \multirow{2}{*}{ GENDER } & MALE & 47 & 38.8 & 59 & 50 \\
\hline & FEMALE & 74 & 61.2 & 59 & 50 \\
\hline \multirow{6}{*}{ AGE } & $18-24$ & 24 & 19.8 & 19 & 16.1 \\
\hline & $25-34$ & 27 & 22.3 & 26 & 22.0 \\
\hline & $35-44$ & 29 & 24.0 & 30 & 25.4 \\
\hline & $45-54$ & 22 & 18.2 & 24 & 20.4 \\
\hline & $55-64$ & 13 & 10.8 & 13 & 11.0 \\
\hline & $65-74$ & 6 & 4.9 & 6 & 5.1 \\
\hline \multirow{7}{*}{$\begin{array}{l}\text { INTENSITY } \\
\text { OF USE OF } \\
\text { THE } \\
\text { INTERNET } \\
\text { (per week) }\end{array}$} & Less than 1 hour & 17 & 14.1 & 1 & 0.8 \\
\hline & Between 1 and 5 hours & 17 & 14.1 & 32 & 27.1 \\
\hline & Between 6 and $10 \mathrm{~h}$. & 26 & 21.5 & 20 & 16.9 \\
\hline & Between 11 and $21 \mathrm{~h}$. & 31 & 25.6 & 22 & 18.7 \\
\hline & Between 22 and $42 \mathrm{~h}$. & 20 & 16.5 & 23 & 19.5 \\
\hline & Between 43 and $60 \mathrm{~h}$. & 8 & 6.6 & 10 & 8.5 \\
\hline & More than 60 hours & 2 & 1.6 & 10 & 8.5 \\
\hline \multirow{7}{*}{$\begin{array}{l}\text { FREQUENCY } \\
\text { OF USE OF } \\
\text { SOCIAL } \\
\text { PLATFORMS }\end{array}$} & Never or hardly ever & 1 & 0.8 & 12 & 10.2 \\
\hline & Once a month & 1 & 0.8 & 3 & 2.5 \\
\hline & 2-3 times per week & 4 & 3.3 & 3 & 2.5 \\
\hline & Once a week & 1 & 0.8 & 11 & 9.3 \\
\hline & Several times a week & 8 & 6.6 & 16 & 13.6 \\
\hline & Once a day & 2 & 1.7 & 12 & 10.2 \\
\hline & Several times a day & 104 & 86.0 & 61 & 51.7 \\
\hline
\end{tabular}

Table 3

Two-way ANOVA test results.

\begin{tabular}{|l|r|r|r|r|r|r|}
\hline \multirow{2}{*}{$\begin{array}{c}\text { Independent } \\
\text { Variables }\end{array}$} & \multicolumn{2}{|c|}{ Attitude toward the firm } & \multicolumn{3}{c|}{ Repurchase intentions } \\
\cline { 2 - 7 } & \multicolumn{1}{|c|}{$\mathrm{F}$} & \multicolumn{1}{c|}{ Sig (p) } & Eta squared & \multicolumn{1}{c|}{ F } & \multicolumn{1}{c|}{ Sig (p) } & Eta squared \\
\hline $\begin{array}{l}\text { Positive valence } \\
\text { intensity (PVI) }\end{array}$ & 0.526 & 0.591 & 0.004 & 1.673 & 0.190 & 0.014 \\
\hline Performance (P) & 1021.243 & 0.000 & 0.814 & 1137.141 & 0.000 & 0.830 \\
\hline PVI*P & 8.059 & 0.000 & 0.065 & 12.977 & 0.000 & 0.100 \\
\hline
\end{tabular}

\section{Table 4}

Means for attitude toward the firm and repurchase intentions.

\begin{tabular}{|c|l|r|r|}
\cline { 2 - 4 } \multicolumn{2}{|c|}{} & High performance & Low Performance \\
\hline \multirow{4}{*}{ Attitude toward the firm } & Neutral-indifferent & 8.30 & 2.55 \\
\cline { 2 - 4 } & Moderately positive & 8.06 & 3.18 \\
\cline { 2 - 4 } & Extremely positive & 8.74 & 2.11 \\
\hline \multirow{3}{*}{ Repurchase intentions } & Neutral-indifferent & 8.04 & 1.58 \\
\cline { 2 - 4 } & Moderately positive & 7.80 & 2.49 \\
\cline { 2 - 4 } & Extremely positive & 8.58 & 0.91 \\
\hline
\end{tabular}


Table 5

Results of the relationship between perceived positivity and post-consumption responses (high performance). ${ }^{\mathrm{a}}$, c, c, d

\begin{tabular}{|c|c|c|c|c|c|c|c|c|}
\hline & \multicolumn{4}{|c|}{ ATTITUDE TOWARD THE FIRM } & \multicolumn{4}{|c|}{ REPURCHASE INTENTIONS } \\
\hline & Model 1 & Model 2 & Model 3 & Model 4 & Model 5 & Model 6 & Model 7 & Model 8 \\
\hline Control variables & & & & & & & & \\
\hline Sex & $\begin{array}{l}-0.030 \\
(-0.16)\end{array}$ & $\begin{array}{l}-0.051 \\
(-0.28)\end{array}$ & $\begin{array}{l}-0.077 \\
(-0.43)\end{array}$ & $\begin{array}{l}-0.076 \\
(-0.42)\end{array}$ & $\begin{array}{l}0.125 \\
(0.65)\end{array}$ & $\begin{array}{l}0.099 \\
(0.53)\end{array}$ & $\begin{array}{l}0.079 \\
(0.43)\end{array}$ & $\begin{array}{l}0.076 \\
(0.41)\end{array}$ \\
\hline Age & $\begin{array}{l}-0.011 \\
(-1.60)\end{array}$ & $\begin{array}{l}-0.131^{*} \\
(-1.80)\end{array}$ & $\begin{array}{l}-0.008 \\
(-1.14)\end{array}$ & $\begin{array}{l}-0.008 \\
(-1.14)\end{array}$ & $\begin{array}{l}-0.002 \\
(-0.28)\end{array}$ & $\begin{array}{l}-0.004 \\
(-0.56)\end{array}$ & $\begin{array}{l}-0.000 \\
(-0.01)\end{array}$ & $\begin{array}{l}-0.000 \\
(-0.02)\end{array}$ \\
\hline Internet experience & $\begin{array}{l}0.855^{* * * *} \\
(3.63)\end{array}$ & $\begin{array}{l}0.818 * * * \\
(3.50)\end{array}$ & $\begin{array}{l}0.749 * * * \\
(3.24)\end{array}$ & $\begin{array}{l}0.753 * * * \\
(3.24)\end{array}$ & $\begin{array}{l}1.081 * * * \\
(4.13)\end{array}$ & $\begin{array}{l}1.037 * * * \\
(3.90)\end{array}$ & $\begin{array}{l}0.982 * * * \\
(3.58)\end{array}$ & $\begin{array}{l}0.954 * * * \\
(3.39)\end{array}$ \\
\hline Main effects & & & & & & & & \\
\hline Perceived positivity (PP) & & $\begin{array}{l}0.078^{*} \\
(1.76)\end{array}$ & $\begin{array}{l}-0.477 * * \\
(-2.54)\end{array}$ & $\begin{array}{l}-0.556 \\
(-1.55)\end{array}$ & & $\begin{array}{l}0.093 * * \\
(2.08)\end{array}$ & $\begin{array}{l}-0.349 * \\
(-1.80)\end{array}$ & $\begin{array}{l}0.126 \\
(0.38)\end{array}$ \\
\hline PP squared & & & $\begin{array}{l}0.048 * * * \\
(3.04)\end{array}$ & $\begin{array}{l}0.065 \\
(0.83)\end{array}$ & & & $\begin{array}{l}0.038 * * \\
(2.34)\end{array}$ & $\begin{array}{l}-0.063 \\
(-0.85)\end{array}$ \\
\hline PP cubic & & & & $\begin{array}{l}-0.001 \\
(-0.20)\end{array}$ & & & & $\begin{array}{l}0.006 \\
(1.28)\end{array}$ \\
\hline Constant & $\begin{array}{l}3.052 * \\
(1.83)\end{array}$ & $\begin{array}{l}2.899 * \\
(1.77)\end{array}$ & $\begin{array}{l}4.527 * * * \\
(2.71)\end{array}$ & $\begin{array}{l}4.588 * * * \\
(2.77)\end{array}$ & $\begin{array}{l}0.682 \\
(0.37)\end{array}$ & $\begin{array}{l}0.499 \\
(0.27)\end{array}$ & $\begin{array}{l}1.798 \\
(0.90)\end{array}$ & $\begin{array}{l}1.429 \\
(0.71)\end{array}$ \\
\hline F-test & $5.30 * * *$ & $5.16^{* * *}$ & $5.11 * * *$ & $4.60 * * *$ & $5.80 * * *$ & $6.37 * * *$ & $7.01 * * *$ & $5.93 * * *$ \\
\hline Wald test: Model 1 vs. & & $3.09 *$ & $6.65 * * *$ & $4.97 * * *$ & & & & \\
\hline Wald test: Model 2 vs. & & & $9.23 * * *$ & $5.81 * * *$ & & & & \\
\hline Wald test: Model 3 vs. & & & & 0.04 & & & & \\
\hline Wald test: Model 5 vs. & & & & & & $4.32 * *$ & $4.84 * * *$ & $3.34 * *$ \\
\hline Wald test: Model 6 vs. & & & & & & & $5.46 * *$ & $2.98 *$ \\
\hline Wald test: Model 7 vs. & & & & & & & & 1.63 \\
\hline
\end{tabular}

${ }^{a}$ Each model provides the estimations of the coefficients and t-values (in parentheses) for the variables considered.

${ }^{\mathrm{b}}$ Significance levels: $* * * \mathrm{p}<0.01, * * \mathrm{p}<0.05, * \mathrm{p}<0.1$, two-tailed tests.

${ }^{c}$ The significance of the F-test for each model indicates its explanatory power.

d The Wald test compares the adequacy of the model indicated in the row with the model indicated in the column. For example, the Wald test included in the last row of this table compare Models 7 and 8 for repurchase intentions. In this case, since the Wald test is not significant, it can be stated that Model 8 provides less explanatory power than Model 7. The penultimate row compares Model 6 with Models 7 and 8 for repurchase intentions. The findings demonstrate that Model 7 has the highest explanatory power. 
Table 6

Results of the relationship between perceived positivity and post-consumption responses (low performance), ${ }^{\mathrm{a}, \mathrm{b}, \mathrm{c}, \mathrm{d}}$

\begin{tabular}{|c|c|c|c|c|c|c|c|c|}
\hline & \multicolumn{4}{|c|}{ ATTITUDE TOWARD THE FIRM } & \multicolumn{4}{|c|}{ REPURCHASE INTENTIONS } \\
\hline & Model 1 & Model 2 & Model 3 & Model 4 & Model 5 & Model 6 & Model 7 & Model 8 \\
\hline Control variables & & & & & & & & \\
\hline Sex & $\begin{array}{c}-0.23 \\
(-0.70)\end{array}$ & $\begin{array}{l}-0.264 \\
(-0.80)\end{array}$ & $\begin{array}{l}-0.129 \\
(-0.40)\end{array}$ & $\begin{array}{l}-0.131 \\
(-0.40)\end{array}$ & $\begin{array}{l}-0.368 \\
(-1.04)\end{array}$ & $\begin{array}{c}0.447 \\
(-1.27)\end{array}$ & $\begin{array}{l}-0.288 \\
(-0.85)\end{array}$ & $\begin{array}{l}-0.308 \\
(-0.90)\end{array}$ \\
\hline Age & $\begin{array}{l}-0.001 \\
(-0.14)\end{array}$ & $\begin{array}{l}-0.001 \\
(-0.08)\end{array}$ & $\begin{array}{l}0.002 \\
(0.18)\end{array}$ & $\begin{array}{l}0.002 \\
(0.18)\end{array}$ & $\begin{array}{l}0.007 \\
(0.60)\end{array}$ & $\begin{array}{l}0.008 \\
(0.70)\end{array}$ & $\begin{array}{l}0.012 \\
(0.98)\end{array}$ & $\begin{array}{l}0.012 \\
(0.95)\end{array}$ \\
\hline Internet experience & $\begin{array}{l}0.242 \\
(0.86)\end{array}$ & $\begin{array}{l}0.248 \\
(0.87)\end{array}$ & $\begin{array}{l}0.454 \\
(1.57)\end{array}$ & $\begin{array}{l}0.452 \\
(1.55)\end{array}$ & $\begin{array}{l}0.105 \\
(0.33)\end{array}$ & $\begin{array}{l}0.118 \\
(0.36)\end{array}$ & $\begin{array}{l}0.361 \\
(1.05)\end{array}$ & $\begin{array}{l}0.347 \\
(1.02)\end{array}$ \\
\hline Main effects & & & & & & & & \\
\hline Perceived positivity (PP) & & $\begin{array}{l}-0.050 \\
(-0.68)\end{array}$ & $\begin{array}{c}0.989 * * * \\
(0.004)\end{array}$ & $\begin{array}{l}0.886 \\
(1.05)\end{array}$ & & $\begin{array}{l}-0.106 \\
(-1.49)\end{array}$ & $\begin{array}{c}1.121 * * * \\
(2.98)\end{array}$ & $\begin{array}{l}0.122 \\
(0.13)\end{array}$ \\
\hline PP squared & & & $\begin{array}{c}-0.089 * * * \\
(0.002)\end{array}$ & $\begin{array}{l}-0.068 \\
(-0.41)\end{array}$ & & & $\begin{array}{c}-0.106^{* * *} \\
(-3.44)\end{array}$ & $\begin{array}{l}0.097 \\
(0.54)\end{array}$ \\
\hline PP cubic & & & & $\begin{array}{l}-0.001 \\
(-0.12)\end{array}$ & & & & $\begin{array}{l}-0.012 \\
(-1.16)\end{array}$ \\
\hline Constant & $\begin{array}{l}1.475 \\
(0.69)\end{array}$ & $\begin{array}{l}1.791 \\
(0.83)\end{array}$ & $\begin{array}{l}-2.520 \\
(-0.96)\end{array}$ & $\begin{array}{l}-2.369 \\
(-0.84)\end{array}$ & $\begin{array}{l}1.322 \\
(0.57)\end{array}$ & $\begin{array}{l}1.992 \\
(0.83)\end{array}$ & $\begin{array}{l}-3.096 \\
(-1.01)\end{array}$ & $\begin{array}{l}-1.631 \\
(-0.49)\end{array}$ \\
\hline F-test & 0.48 & 0.47 & $2.31 * *$ & $1.93 *$ & 0.45 & 0.89 & $3.64 * * *$ & $3.87 * * *$ \\
\hline Wald test vs. (Models 1) & & 0.46 & $5.24 * * *$ & $3.52 * *$ & & & & \\
\hline Wald test vs. (Models 2) & & & $10.09 * * *$ & $5.13 * *$ & & & & \\
\hline Wald test vs. (Models 3) & & & & 0.01 & & & & \\
\hline Wald test vs. (Models 5) & & & & & & 2.22 & $8.87 * * *$ & $7.58 * * *$ \\
\hline Wald test vs. (Models 6) & & & & & & & $11.84 * * *$ & $7.45 * * *$ \\
\hline Wald test vs. (Models 7) & & & & & & & & 1.36 \\
\hline
\end{tabular}

${ }^{a}$ Each model provides the estimations of the coefficients and t-values (in parentheses) for the variables considered.

${ }^{\mathrm{b}}$ Significance levels: $* * * \mathrm{p}<0.01, * * \mathrm{p}<0.05, * \mathrm{p}<0.1$, two-tailed tests.

${ }^{c}$ The significance of the F-test for each model indicates its explanatory power.

d The Wald test compares the adequacy of the model indicated in the row with the model indicated in the column. For example, the Wald test included in the last row of this table compare Models 7 and 8 for repurchase intentions. In this case, since the Wald test is not significant, it can be stated that Model 8 provides less explanatory power than Model 7. The penultimate row compares Model 6 with Models 7 and 8 for repurchase intentions. The findings demonstrate that Model 7 has the highest explanatory power. 


\section{Table 7}

Results for the (inverted) U-shaped relationships for post-consumption responses (robust estimations).

\begin{tabular}{|c|c|c|c|c|}
\hline & \multicolumn{2}{|c|}{ LOW PERFORMANCE } & \multicolumn{2}{|c|}{ HIGH PERFORMANCE } \\
\hline & $\begin{array}{c}\text { Attitude toward } \\
\text { the firm }\end{array}$ & $\begin{array}{c}\text { Repurchase } \\
\text { Intentions } \\
\end{array}$ & $\begin{array}{c}\begin{array}{c}\text { Attitude toward the } \\
\text { firm }\end{array} \\
\end{array}$ & $\begin{array}{l}\text { Repurchase } \\
\text { Intentions } \\
\end{array}$ \\
\hline Slope at the low end (XL) & $0.811 * * *$ & $0.910 * * *$ & $-0.477 * * *$ & $-0.349 * *$ \\
\hline t-value & $(2.92)$ & $(2.87)$ & $(-2.54)$ & $(-1.80)$ \\
\hline Slope at the high end $(\mathrm{XH})$ & $-0.797 * * *$ & $-0.988 * * *$ & $0.497 * * *$ & $0.428 * * *$ \\
\hline t-value & $(-3.22)$ & $(-3.95)$ & $(3.480)$ & $(2.84)$ \\
\hline Turning point & 5.54 & 5.53 & 4.89 & 4.49 \\
\hline $\begin{array}{l}95 \% \text { Fieller interval for } \\
\text { extreme point }\end{array}$ & $(4.38-6.39)$ & $(3.97-5.92)$ & $(2.86-5.70)$ & $(-2.71-5.64)$ \\
\hline U-test (p-value) & $2.92 * * *(0.002)$ & $2.88 * * *(0.000)$ & $2.54 * * *(0.006)$ & $1.80 * *(0.037)$ \\
\hline
\end{tabular}
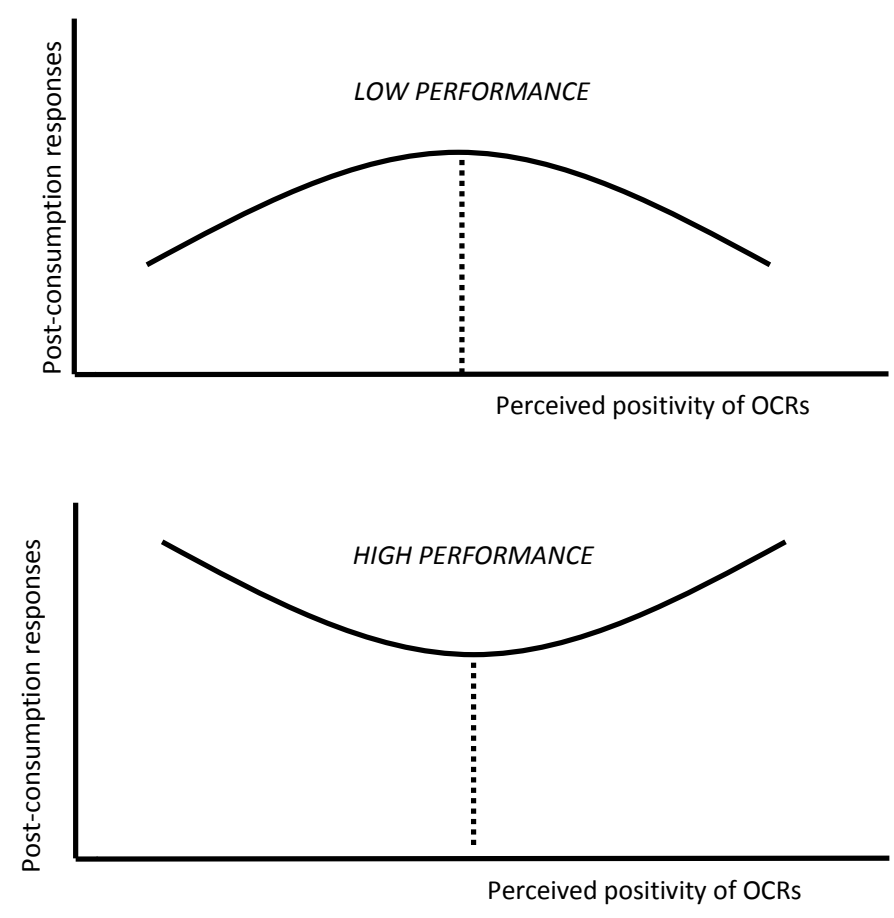

Fig. 1. U-shaped functional forms proposed for the relationship between perceived positivity and post-consumption responses. 


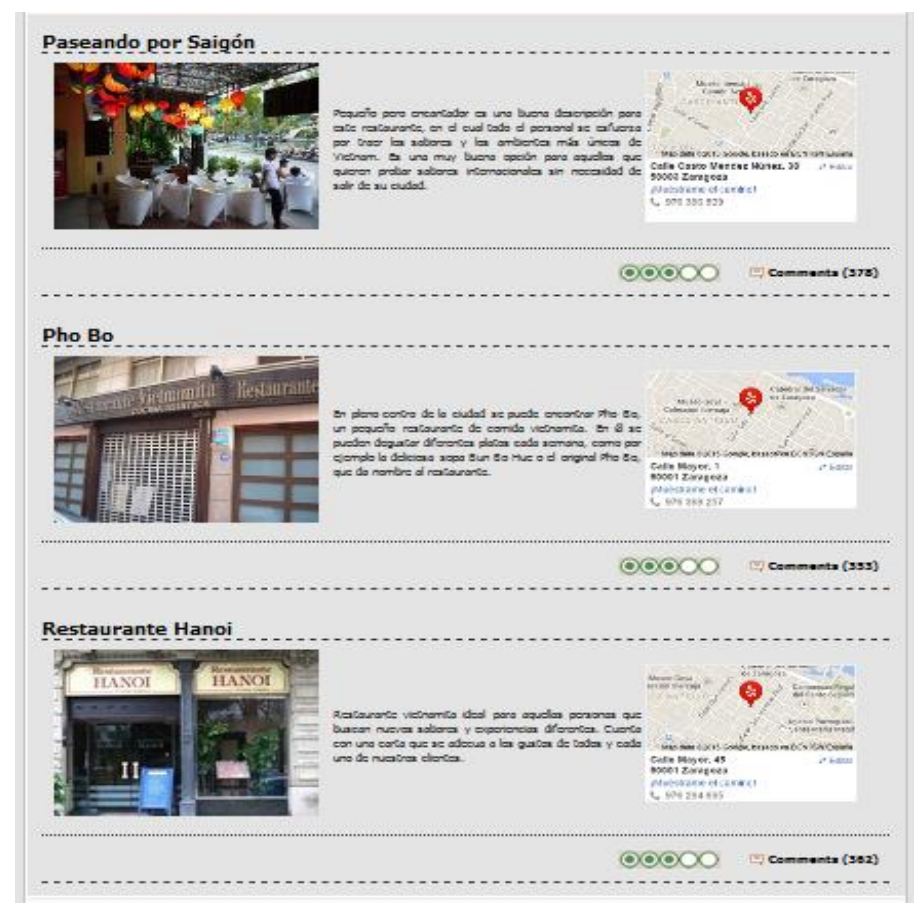

General information about the three restaurants

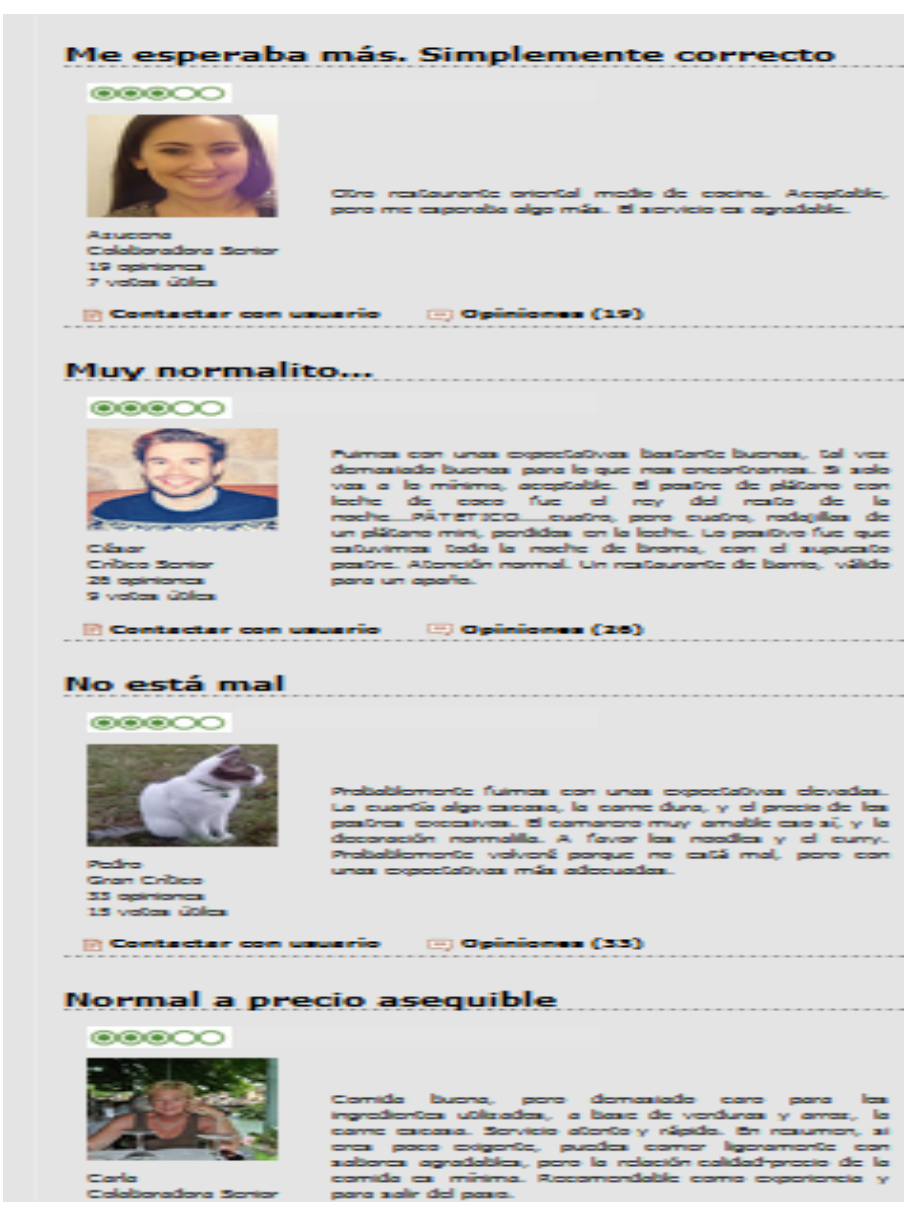

Example of OCRs

Fig. 2. Screenshots of the experimental design. 


\section{WHEN THE PERFORMANCE COMES INTO PLAY: THE INFLUENCE OF POSITIVE ONLINE CONSUMER REVIEWS ON INDIVIDUALS' POST- CONSUMPTION RESPONSES}

\section{Highlights}

Positive OCRs and performance jointly influence post-consumption responses

Positive OCRs can have negative effects on post-consumption responses

Relationships between individuals' perceived positivity of OCRs and their post-

consumption responses follow curvilinear functional forms

If the performance is low, inverted U-shaped relationships are identified

If the performance is high, U-shaped relationships are identified 


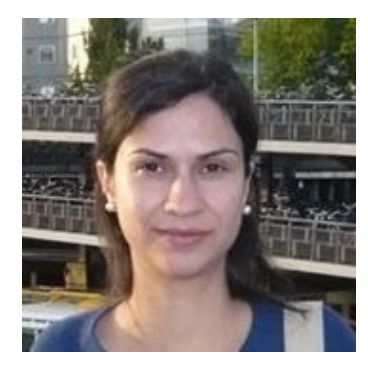

Ph.D. Blanca Hernandez-Ortega is an associate professor of marketing at the University of Zaragoza (Spain). Her research interests include the acceptance of new technologies, digital marketing, social media, and online consumer behaviour. Her work has been presented in conferences and published in several academic journals such as Information \& Management (2), Industrial Marketing Management, European Journal of Marketing, Journal of Business Research, Technovation (2), Internet Research (3), Journal of Electronic Commerce, Services Industries Journal, Service Business (2), Computers \& Education, Online Information Review (2), International Journal of Information Management, Journal of Business and Industrial Marketing, Information Research and Computers in Human Behavior, among others. 